PNNL-10989

UC-810

Project Technical Information

RECEIVED

APR 011996

OSTI

Annual Progress Report to Battelle

Pacific Northwest National

Laboratories on Prediction of Phase

Separation of Simulated Nuclear

Waste Glasses

Y.-M. Sung

M. Tomozawa

February 1996

Prepared for

the U.S. Department of Energy

under Contract DE-AC06-76RLO 1830

Pacific Northwest National Laboratory

Richland, Washington 99352

*ate Battelle 
PNNL-10989

UC-810

Project Technical Information

\title{
Annual Progress Report to Battelle Pacific Northwest Laboratories on Prediction of Phase Separation of Simulated Nuclear Waste Glasses
}

\author{
Y.-M. Sung \\ M. Tomozawa
}

February 1996

Prepared for

the U.S. Department of Energy

under Contract DE-AC06-76RLO 1830

Pacific Northwest National Laboratory

Richland, Washington 99352

Reprint of historical document PVTD-C95-02.01GG, dated August 15, 1995. Prepared for Pacific Northwest Laboratory by the Department of Materials Science and Engineering at the Rensselaer Polytechnic Institute in Troy, NY. Data, formatting, and other conventions reflect standards at the original date of printing. Technical peer reviews and editorial teviews may not have been performed. 


\section{DISCLAIMER}

This report was prepared as an account of work sponsored by an agency of the United States Government. Neither the United States Government nor any agency thereof, nor Battelle Memorial Institute, nor any of their employees, makes any warranty, express or implied, or assumes any legal liability or responsibility for the accuracy, completeness, or.usefulness of any information, apparatus, product, or process disclosed, or represents that its use would not infringe privately owned rights. Reference herein to any specific commercial product, process, or service by trade name, trademark, manufacturer, or otherwise does not necessarily constitute or imply its endorsement, recommendation, or favoring by the United States Government or any agency thereof, or Battelle Memorial Institute. The views and opinions of authors expressed herein do not necessarily state or reflect those of the United States Government or any agency thereof.

\section{PACIFIC NORTHWEST NATIONAL LABORATORY operated by BATTELLE for the UNITED STATES DEPARTMENT OF ENERGY under Contract DE-AC06-76RLO 1830}

Printed in the United States of America

Available to DOE and DOE contractors from the

Office of Scientific and Technical Information, P.O. Box 62, Oak Ridge, TN 37831; prices available from (615) 576-840\%.

Available to the public from the National Technical Information Service, U.S. Department of Commerce, 5285 Port Royal Rd., Springfield, VA 22161 


\section{Introduction:}

This annual progress report covers the results obtained during the first year (August 15, 1994 - August 14, 1995) of the project. The objective of this research is to predict the immiscibility boundaries of multi-component boro-silicate glasses, on which many nuclear waste glass compositions are based. The method used is similar to the prediction method of immiscibility boundaries of multi-component silicate glass systems successfully made earlier ${ }^{1-3}$ and is based upon the superposition of immiscibility boundaries of simple systems using an appropriate parameter. This method is possible because many immiscibility boundaries have similar shapes and can be scaled by a parameter. In the alkali and alkaline earth binary silicate systems, for example, the critical temperature and compositions were scaled ${ }^{4}$ using the DebyeHückel theory. In the present study on boro-silicate systems, first, immiscibility boundaries of various binary alkali and alkaline borate glass systems (e.g. $\mathrm{BaO}-\mathrm{B}_{2} \mathrm{O}_{3}$ ) were examined and their critical temperatures were evaluated in terms of Debye-Hũckel theory. The mixing effects of two alkali and alkaline-earth borate systems on the critical temperature were also explored. Next immiscibility boundaries of ternary boro-silicate glasses (e.g. $\mathrm{Na}_{2} \mathrm{O}-\mathrm{SiO}_{2}-\mathrm{B}_{2} \mathrm{O}_{3}, \mathrm{~K}_{2} \mathrm{O}-\mathrm{SiO}_{2}-\mathrm{B}_{2} \mathrm{O}_{3}$, $\mathrm{Rb}_{2} \mathrm{O}-\mathrm{SiO}_{2}-\mathrm{B}_{2} \mathrm{O}_{3}$, and $\mathrm{Cs}_{2} \mathrm{O}-\mathrm{SiO}_{2}-\mathrm{B}_{2} \mathrm{O}_{3}$ ) were examined. Their mixing effects are currently under investigation.

\section{Experimental Procedures:}

High purity powders (e.g. alkali and alkaline-earth carbonates, $\mathrm{SiO}_{2}$ and $\mathrm{B}_{2} \mathrm{O}_{3}$ ) from Fisher Scientific Company were used for glass preparation. The weight of each glass batch was $20 \mathrm{~g}$. The powders were mixed using a mortar and pestle. For each composition the entire batch mixture was used to obtain a melt. A CM Rapid Temperature Fumace (maximum temperature of $1600^{\circ} \mathrm{C}$ ) and a platinum crucible were used for melting. The furnace was rate-heated to 1400 ${ }^{\circ} \mathrm{C}$ over an $1 \mathrm{hr}$ period and held at $1400^{\circ} \mathrm{C}$ for $1.5 \mathrm{hr}$ for melt homogenization. The glass melts were then poured onto a brass plate and any glass remaining inside the crucible was quenched in water.

The glass chunks $\left(\sim 1^{\prime \prime} \times 1.8^{\prime \prime} \times 0.2^{\prime \prime}\right)$ were broken into small pieces by using a hammer. Glass fragments of about $0.5^{n}$ diameter were used for the immiscibility boundary determination. For systems with comparatively high immiscibility temperatures having fast phase separation 
kinetics, the immiscibility temperature was determined in-situ. For this purpose, using a Thermolyne Furnace (type 48000 ) and a platinum boat ( $-3.5^{n}$ long), direct observation of the

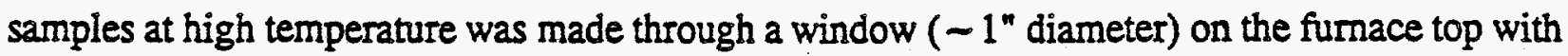
a metal cover. Opening this cover did not affect the fumace temperature. A strong flash light was used to observe the glass samples at high temperatures directly through the window. Only one glass sample was loaded at a time inside the platinum boat since most of the glasses had very low melt viscosities. The furnace temperature was increased or decreased by 3 to $5{ }^{\circ} \mathrm{C}$ increments. The phase separation or clearing occurred rapidly, and holding the furnace at each temperature for $3 \mathrm{~min}$ was sufficient. For specimens with lower immiscibility temperature having slow phase separation kinetics, the glasses were heat-treated for longer time and the opalescence was examined after quenching.

\section{Results}

\section{(A) Binary alkali and alkaline-earth borate systems}

Fig. 1 shows the immiscibility boundaries of $\mathrm{BaO}-\mathrm{B}_{2} \mathrm{O}_{3}$ glass system, determined in this study. The critical temperature was $1180{ }^{\circ} \mathrm{C}$ and critical composition was about 84 wt $\% \mathrm{~B}_{2} \mathrm{O}_{3}$. This result is very close to our previous study $y^{5}$ For alkali borate systems there have been some published immiscibility boundaries ${ }^{6,7}$. The most reliable data are those on $\mathrm{Li}_{2} \mathrm{O}-\mathrm{B}_{2} \mathrm{O}_{3}$ by Golubkov et al. ${ }^{7}$ with a critical temperature $454^{\circ} \mathrm{C}$. The immiscibility temperature for the $\mathrm{Na}_{2} \mathrm{O}$ $\mathrm{B}_{2} \mathrm{O}_{3}$ system is expected to be too low to be observed experimentally, while that of $\mathrm{SrO}-\mathrm{B}_{2} \mathrm{O}_{3}$ is expected to be too high. Thus the immiscibility temperatures of ternary $\mathrm{Na}_{2} \mathrm{O}-\mathrm{SrO}_{2}-\mathrm{B}_{2} \mathrm{O}_{3}$ system were examined and extrapolated to immiscibility temperature of binary $\mathrm{Na}_{2} \mathrm{O}-\mathrm{B}_{2} \mathrm{O}_{3}$ and $\mathrm{SrO}-\mathrm{B}_{2} \mathrm{O}_{3}$ systems to estimate the respective binary immiscibility boundaries. At the same time the study of the critical temperature of these ternary systems examines the effect of mixing of two alkalis and alkaline-earth components. Similarly, the critical temperature of the $\mathrm{Li}_{2} \mathrm{O}-\mathrm{BaO}-$ $\mathrm{B}_{2} \mathrm{O}_{3}$ system was also examined. Figure 2 shows the glass compositions investigated and the critical temperatures obtained for binary and temary borate systems are shown in Table 1. Figures 3 and 4 show the critical temperature variation with the mixing ratio of alkali to alkaline earth component. As can be seen a reasonable linear relationship was observed for both ternary systems, indicating that the critical temperature of the ternary borate systems can be estimated 
by the arithmetic average of two critical temperatures of the two binary borate systems. Furthermore, in the case of the $\mathrm{Li}_{2} \mathrm{O}-\mathrm{BaO}-\mathrm{B}_{2} \mathrm{O}_{3}$ system, the linear line passes through the binary critical temperatures of respective binary borate systems determined separately. This suggests that an extrapolation of the critical temperature of $\mathrm{Na}_{2} \mathrm{O}-\mathrm{SrO}-\mathrm{B}_{2} \mathrm{O}_{3}$ can be used to estimate the critical temperatures of both the $\mathrm{Na}_{2} \mathrm{O}-\mathrm{B}_{2} \mathrm{O}_{3}$ and $\mathrm{SrO}-\mathrm{B}_{2} \mathrm{O}_{3}$ systems. With these measurements, the critical temperatures of binary borate systems, $\mathrm{Li}_{2} \mathrm{O}-\mathrm{B}_{2} \mathrm{O}_{3}, \mathrm{Na}_{2} \mathrm{O}-\mathrm{B}_{2} \mathrm{O}_{3}, \mathrm{SrO}-\mathrm{B}_{2} \mathrm{O}_{3}$ and $\mathrm{BaO}-$ $\mathrm{B}_{2} \mathrm{O}_{3}$, were estimated.

Earlier, we found $d^{4}$ that the critical temperatures, $T_{e}$, of various binary silicate glass systems can be expressed by

$$
T_{c}=Z_{+} Z_{-} e_{0}^{2} /\left(64 \pi \epsilon_{t} \epsilon_{0} k a\right)
$$

where $Z_{+}, Z_{0}$ are valences, $e_{0}$ the charge on an electron, $\epsilon_{r}$ the relative dielectric constant of $\mathrm{SiO}_{2}$ (3.8) or $\mathrm{B}_{2} \mathrm{O}_{3}(3.2), \epsilon_{\mathrm{o}}$ the permittivity of free space $\left(8.85 \times 10^{-12} \mathrm{~F} / \mathrm{m}\right), k$ Boltzmann's constant $\left(1.38 \times 10^{-23} \mathrm{~J} / \mathrm{K}\right)$, and $a$ the distance of closest approach between cations and anions in the solution. The critical temperatures of binary borate systems obtained here are plotted in Figure 5 together with those of binary silicate systems. It is clear that the data for borate systems do not fall on the same line as those for silicate systems. In the use of the equation (1), $a$ was taken as the sum of the oxygen radius and cation radius. Examples of the values of a by this method are shown in Table 2. This is reasonable for silicate systems since cations are expected to be bonded ionically to non-bridging oxygen ions. However, this would not be the case for borate systems since the coordination number of boron changes from 3 to 4 as alkali is added to boron oxide, and non-bridging oxygen is not created. In this case the $\mathrm{BO}_{4}$ unit works as an anion as shown in Figure 6. The anion-cation distance, $a$, then becomes the distance between the 4coordinated boron and cation and is shown in Table 3. When this new anion-cation distance was used as the value of a in borate glass systems, the critical temperatures of both borate and silicate systems fell on a single line as shown in Figure 7.

(B) Ternary alkali boro-silicate systems

Immiscibility boundaries of various alkali boro-silicate have been reported ${ }^{8,9}$. But in the course of the present research it was found that the accuracy of some of these data are not high 
and that their re-examination is necessary. Thus all the alkali boro-silicate immiscibility boundaries were remeasured. The results for $\mathrm{SiO}_{2}-\mathrm{B}_{2} \mathrm{O}_{3}-\mathrm{Na}_{2} \mathrm{O}(\mathrm{SBN}), \mathrm{SiO}_{2}-\mathrm{B}_{2} \mathrm{O}_{3}-\mathrm{K}_{2} \mathrm{O}(\mathrm{SBK})$, $\mathrm{SiO}_{2}-\mathrm{B}_{2} \mathrm{O}_{3}-\mathrm{Rb}_{2} \mathrm{O}(\mathrm{SBR})$, and $\mathrm{SiO}_{2}-\mathrm{B}_{2} \mathrm{O}_{3}-\mathrm{Cs}_{2} \mathrm{O}(\mathrm{SBC})$ glasses are shown in Fig. 8. The $\mathrm{SiO}_{2}-\mathrm{B}_{2} \mathrm{O}_{3}-$ $\mathrm{Li}_{2} \mathrm{O}(\mathrm{SBL})$ glass is not included in this figure since there still exist some uncertainties about the critical temperature and critical composition of the SBL glass, especially in the high silica ( -85 mol \%) region. Among the four alkali boro-silicate systems investigated the SBN glass showed the largest immiscibility region, whereas the SBC glass showed the smallest immiscibility area. This trend is consistent with the variation of the field strength difference of alkali ions. That is, the $\mathrm{Na}^{+}$ion has the highest field strength, whereas the $\mathrm{Cs}^{+}$ion has the lowest field strength among the four alkali ions. The critical temperature and critical composition values were different from those of previous works ${ }^{8,9}$ to some degree. For example, all of the glasses showed higher critical temperature values than reported previousily, especially the SBR glass which had an approximately $50^{\circ} \mathrm{C}$ higher critical temperature than previously reported. Also, the SBK, and SBR glasses showed higher $\mathrm{SiO}_{2}$ contents in their critical compositions than the reported values. Table 4 lists the critical temperature and composition values both from present study and previous works. ${ }^{8,9}$ The effects of mixing two alkali boro-silicate glass systems, $\mathrm{SiO}_{2}$ $\mathrm{B}_{2} \mathrm{O}_{3}-\mathrm{Na}_{2} \mathrm{O}(\mathrm{SBN})$, and $\mathrm{SiO}_{2}-\mathrm{B}_{2} \mathrm{O}_{3}-\mathrm{K}_{2} \mathrm{O}(\mathrm{SBK})$ is under investigation. It appears that the critical temperature of the mixed system can be obtained as an arithmetic average of the critical temperatures of two ternary boro-silicate systems involved.

\section{Discussion}

The immiscibility boundaries, especially the critical temperature, of borate systems were found to scale with the parameter, $\mathrm{Z} / \mathrm{a}$, used in the Debye-Hückel model suggesting that the Coulombic interaction is the origin of the immiscibility tendency of these oxide glass systems similar to silicate glasses and melts. Furthermore, the critical temperatures of mixtures of borate or boro-silicate systems were found to be equal to the arithmetic averages of the critical temperatures of the respective borate or boro-silicate systems. This is in contrast to our earlier observation that the critical temperature of the silicate glass systems containing two alkali components systematically deviates from the arithmetic average of the two critical temperatures of the binary silicate systems involved, the deviation being larger for larger differences in ionic sizes of two alkalis ${ }^{20}$. The direction of the deviation indicated that the two alkali components (or 
alkali silicate components) have a positive enthalpy of mixing. Apparently, the enthalpy of mixing between two borates or boro-silicates is nearly zero.

The critical temperature, $T_{e}$, of ternary boro-silicate systems also appears to follow a qualitatively similar trend, with the system having the higher cationic field strength exhibiting the higher critical temperature. Quantitatively, however, equation (1) can not be used to represent the critical temperature of ternary systems. In order to obtain equations for the critical temperature and composition of ternary systems, the regular solution model was used ${ }^{11}$ even though it is not expected to describe ionic systems perfectly. According to the regular solution model, the critical temperature of a ternary system is given by

$$
T_{c}=-\omega_{12} / 8 \mathrm{R}-\left(\omega_{13}-\omega_{22}\right)^{2} / 8 \mathrm{R} \omega_{12}+\left(\omega_{13}+\omega_{22}\right) / 4 \mathrm{R}
$$

where $\omega_{12}, \omega_{13}$, and $\omega_{23}$ are the interaction energy parameters between each component $(1,2$, and 3 denote $\mathrm{SiO}_{2}, \mathrm{~B}_{2} \mathrm{O}_{3}$, and alkali oxide, respectively) and $\mathrm{R}$ is the gas constant. The values of $\omega_{13}$ for alkali-silicate and $\omega_{23}$ for alkali borate are expected to be proportional to the parameter, $\mathrm{Z}+\mathrm{Z} / \mathrm{a}\left(\mathrm{Z}_{+}, \mathrm{Z}\right.$. are the valences of anion and cation and " $\mathrm{a}$ " is the sum of anionic and cationic radius, as used in Figure 7$)^{4}$. Similarly, the critical composition of ternary regular solutions is given by ${ }^{13}$

$$
\begin{aligned}
& X_{c}=\left(\omega_{12}+\omega_{23}-\omega_{13}\right) / 4 \omega_{12}=0.25-\left(\omega_{13}-\omega_{23}\right) / 4 \omega_{12} \\
& Y_{c}=\left(\omega_{12}+\omega_{13}-\omega_{23}\right) / 4 \omega_{12}=0.25+\left(\omega_{13}-\omega_{23}\right) / 4 \omega_{12} \\
& Z_{c}=1-\left(X_{c}+Y_{c}\right)=1-0.5=0.5
\end{aligned}
$$

where $\mathrm{X}_{t}, \mathrm{Y}_{s}$, and $\mathrm{Z}_{t}$ are the mole fractions of $\mathrm{SiO}_{2}, \mathrm{~B}_{2} \mathrm{O}_{3}$, and $\mathrm{R}_{2} \mathrm{O}$ at the critical composition. It is not expected that these equations would represent the critical temperatures and compositions of temary boro-silicate systems since unlike this regular solution model, real ternary systems do not have the symmetric immiscibility boundaries. However, by adjusting compositions using appropriate parameters, it should be possible to bring the real immiscibility boundaries close to that of the regular solution as was done for binary silicate systems by Haller et al. ${ }^{12}$ Even without adjusting the compositions, the above equations can predict the tendencies in $T_{c}$ and $X_{c}, Y_{c}$, and $Z_{c}$ values. For example, from this theory $Z_{c}$ is a constant for the ternary 
alkali boro-silicate glasses which is consistent with the experimental results. Furthermore, since $\omega_{13}>\omega_{23}$ and $\omega_{12}<0$, it can be predicted that the $X_{c}$ vs. $z / a$ plot has a positive slope and the $Y_{c}$ vs. $z / a$ plot has a negative slope. Experimental observations are consistent with these expectations.

By adjusting component compositions by appropriate parameters such that the above equations (2)-(5) predict the real ternary immiscibility boundaries, the possibility of superposing various ternary immiscibility boundaries can be examined. It should be possible to extend this analysis. to multi-component alkali-alkaline earth boro-silicate systems since the critical temperature of a mixture system of borate and boro-silicate systems was found to be the average of the two systems involved. This average critical temperature of the mixture of borate and borosilicate systems is interesting phenomenon, in addition to being a practically useful one.

\section{Conclusions}

The immiscibility boundaries including critical temperatures and compositions of both binary borate systems and alkali bora-silicate glasses were examined. The critical temperature, $T_{e}$, of both borate systems and alkali borate systems appear to scale with field strength of cations, i.e. $z / a$ where $z$ is cationic valence and $a$ is anion-to-cation distance provided that the effective cation size is used. Furthermore, for both borate and boro-silicate systems, the critical temperature of the mixture of two systems was equal to the average of the critical temperature of the two systems involved. This fact makes the prediction of the critical temperature of the multi-component systems easier.

\section{Future work}

The superpositions of various boro-silicate systems will be made using an appropriate parameters. From this superposition, the immiscibility boundaries of multi-component of borosilicate glass systems will be predicted and compared with the experimental data. 


\section{References:}

1. Y. Kawamoto and M. Tomozawa, Phys. Chem. Glasses, 22, (1981) 11.

2. Y. Kawamoto and M. Tomozawa, J. Am. Ceram. Soc., 64 (1981) 289.

3. Y. Kawamoto and M. Tomozawa, J. Non-Cryst. Solids, 43 (1981) 417.

4. V. McGahay and M. Tomozawa, J. Non-Cryst. Solids, 109 (1989) 27.

5. K. Clemens, M. Yoshiyagawa, and M. Tomozawa; J. Am. Ceram. Soc., 64 (1981) C-91.

6. R.R. Shaw and D.R. Uhlmann, J. Am. Ceram. Soc., 51 (1968) 377.

7. V.V. Golubkov, A.P. Titov, T.N. Vasilevskaya and E.A. Porai-Koshits, Fiz. Khim. Stekla, 3 (1977) 312.

8. W. Haller, D. H. Blackburn, F. E. Wagstaff, and R. J. Charles, J. Am. Ceram. Soc., 53 (1970) 34.

9. F. Y. Galakhov, V. I. Aver'yanov, B. T. Vavilonova, and M. P. Areshev, Fizika I Khimiya Stekla, 7, (1981) 38.

10. Y. Kawamoto and M. Tomozawa, Phys. Chem. Glasses, 23 (1982) 72.

11. J. L. Meijering, Philips Res. Rep., 5, (1950) 333.

12. W. Haller, D.H. Blackbum and J.H. Simmons, J. Am. Ceram. Soc., 54 (1974) 299. 
Table 1. The compositions and clearing temperatures of ternary alkali- or alkaline-earth glasses prepared for present study.

\begin{tabular}{|c|c|c|c|c|c|c|}
\hline \multirow[b]{2}{*}{ Glasses } & \multicolumn{5}{|c|}{ Compositions (mol\%) } & \multirow{2}{*}{$\begin{array}{c}\text { Clearing } \\
\text { Temperatures }\left({ }^{\circ} \mathrm{C}\right)\end{array}$} \\
\hline & $\mathrm{BaO}$ & $\mathrm{Li}_{2} \mathrm{O}$ & SrO & $\mathrm{Na}_{2} \mathrm{O}$ & $\mathrm{B}_{3} \mathrm{O}_{3}$ & \\
\hline $\mathrm{BB1}$ & 92.6 & - & - & - & 7.4 & 1180 \\
\hline BB2 & 91.2 & - & - & - & 8.8 & 1175 \\
\hline BB3 & 93.9 & - & - & : & 6.1 & 1170 \\
\hline BB4 & 89.8 & - & - & - & 10.2 & 1150 \\
\hline BB5 & 95.2 & - & - & - & 4.8 & 1145 \\
\hline BB6 & 88.4 & - & - & - & 11.6 & 1100 \\
\hline BB7 & 96.4 & - & - & - & 5.6 & 1095 \\
\hline BLBI & 0.90 & 5.10 & 94.00 & - & - & 833 \\
\hline BLB2 & 1.25 & 3.75 & 95.00 & - & - & 915 \\
\hline SNBI & $\cdot$ & - & 0.50 & 0.50 & 99.00 & 1058 \\
\hline SNB2 & - & - & 1.25 & 0.75 & 98.00 & 1190 \\
\hline SNB3 & - & - & 1.50 & 0.50 & 98.00 & 1338 \\
\hline SNB4 & - & - & 1.75 & 0.25 & 98.00 & 1411 \\
\hline
\end{tabular}


Table 2. The cation-oxygen ion separation of alkali oxides.

\begin{tabular}{cc}
\hline Cations & Separation, a (nm) \\
\hline $\mathrm{Na}^{*}$ & 24.03 \\
$\mathrm{~K}^{+}$ & 27.87 \\
$\mathrm{Rb}^{+}$ & 29.25 \\
$\mathrm{Cs}^{*}$ & 31.06 \\
\hline
\end{tabular}


Table 3. The cation-anion separations of alkali- and alkaline-earth borate glasses.

\begin{tabular}{cc}
\hline Cations & Separation, a (nm) \\
\hline $\mathrm{K}$ & 41.7 \\
$\mathrm{Na}$ & 37.9 \\
$\mathrm{Li}$ & 34.3 \\
$\mathrm{Ba}$ & 41.9 \\
$\mathrm{Sr}$ & 40.0 \\
$\mathrm{Ca}$ & 37.4 \\
$\mathrm{Mg}$ & 34.9 \\
\hline
\end{tabular}


Table 4. The critical compositions and temperatures of ternary alkali borosilicate glasses prepared for present study.

\begin{tabular}{ccccc}
\hline & \multicolumn{2}{c}{ Critical compositions (mol\%) } & Critical temperatures $\left(^{\circ} \mathrm{C}\right)$ \\
\cline { 2 - 4 } Glasses & $\mathrm{SiO}_{2}$ & $\mathrm{~B}_{2} \mathrm{O}_{3}$ & $\mathrm{R}_{2} \mathrm{O}$ & \\
\hline SBN & 75.0 & 20.8 & 4.2 & 775 \\
& $*(75.0)$ & $(20.8)$ & $(4.2)$ & $(770)$ \\
SBK & 68.0 & 28.0 & 4.0 & \\
& $(60.0)$ & $(35.0)$ & $(5.0)$ & 635 \\
& & & & $(620)$ \\
SBR & 65.0 & 30.9 & 4.1 & 605 \\
& $(62.0)$ & $(34.0)$ & $(4.0)$ & $(556)$ \\
SBC & 59.0 & 36.7 & 4.3 & 555 \\
& $(59.0)$ & $(37.0)$ & $(4.0)$ & $(526)$ \\
\hline
\end{tabular}

* Date from ref. 8; Other data in parenthesis from ref. 9. 


\section{Figure Captions}

Figure 1. Immiscibility boundary of the $\mathrm{BaO}-\mathrm{B}_{2} \mathrm{O}_{3}$ system.

Figure 2. Compositions of glasses investigated in the $\mathrm{BaO}-\mathrm{Li}_{2} \mathrm{O}-\mathrm{B}_{2} \mathrm{O}_{3}$ system and $\mathrm{SrO}-\mathrm{Na}_{2} \mathrm{O}-\mathrm{B}_{2} \mathrm{O}_{3}$ system.

Figure 3. The critical temperature of the $\mathrm{BaO}-\mathrm{Li}_{2} \mathrm{O}-\mathrm{B}_{2} \mathrm{O}_{3}$ system.

Figure 4. The critical temperature of the $\mathrm{SrO}-\mathrm{Na}_{2} \mathrm{O}-\mathrm{B}_{2} \mathrm{O}_{3}$ system.

Figure 5. The critical temperatures of binary silicates and binary borates using non-bridging oxygen-cation distance as the parameter.

Figure 6. Schematic diagram of $\mathrm{BO}_{4}^{-}-\mathrm{Na}^{+}$structure.

Figure 7. The critical temperatures of binary silicates using non-bridging oxygen-cation distance as the parameter and binary borates using $\mathrm{BO}_{4}$-cation distance as the parameter.

Figure 8. Immiscibility boundaries of temary alkali boro-silicate systems. 


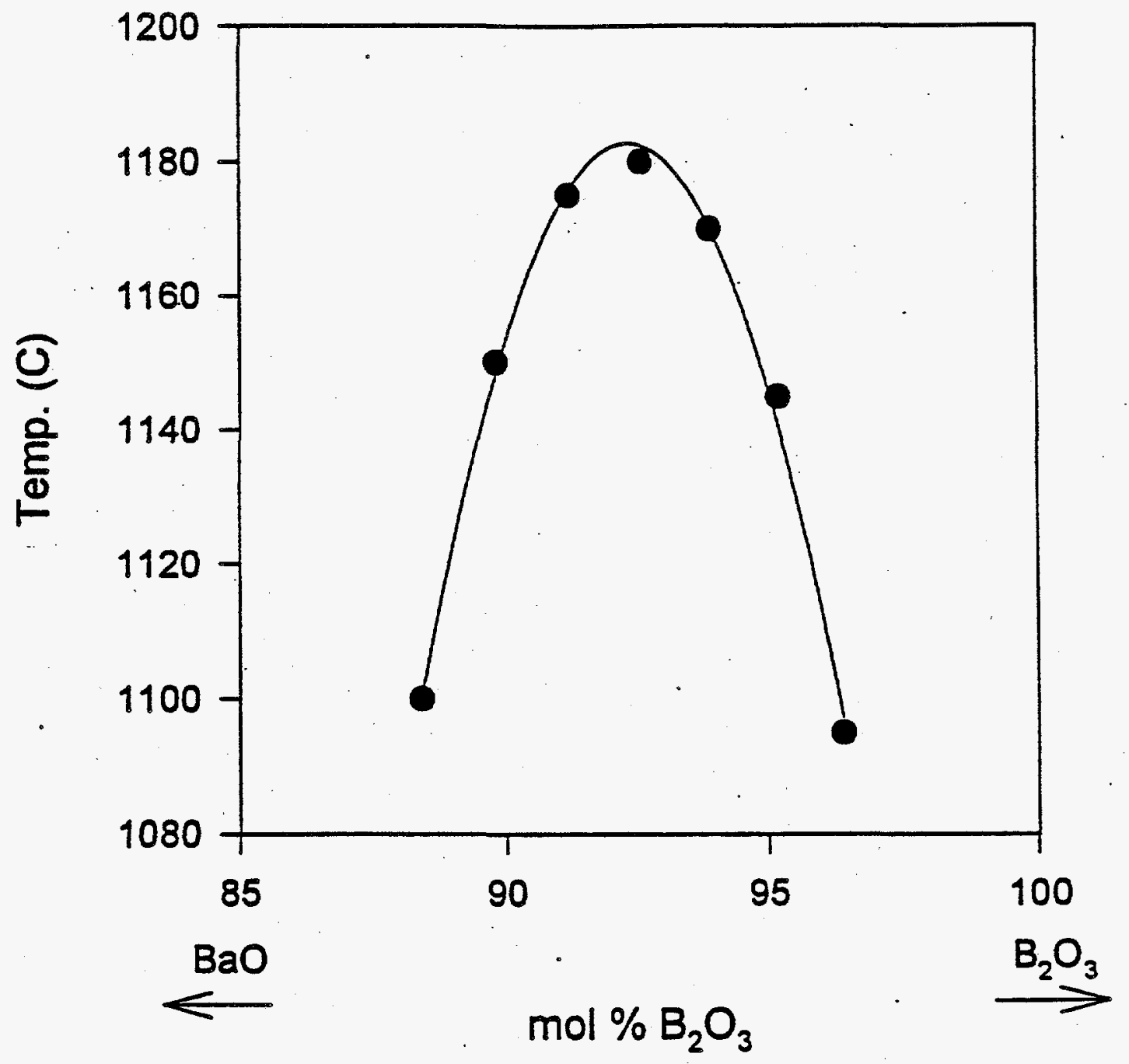

Fig. 1 


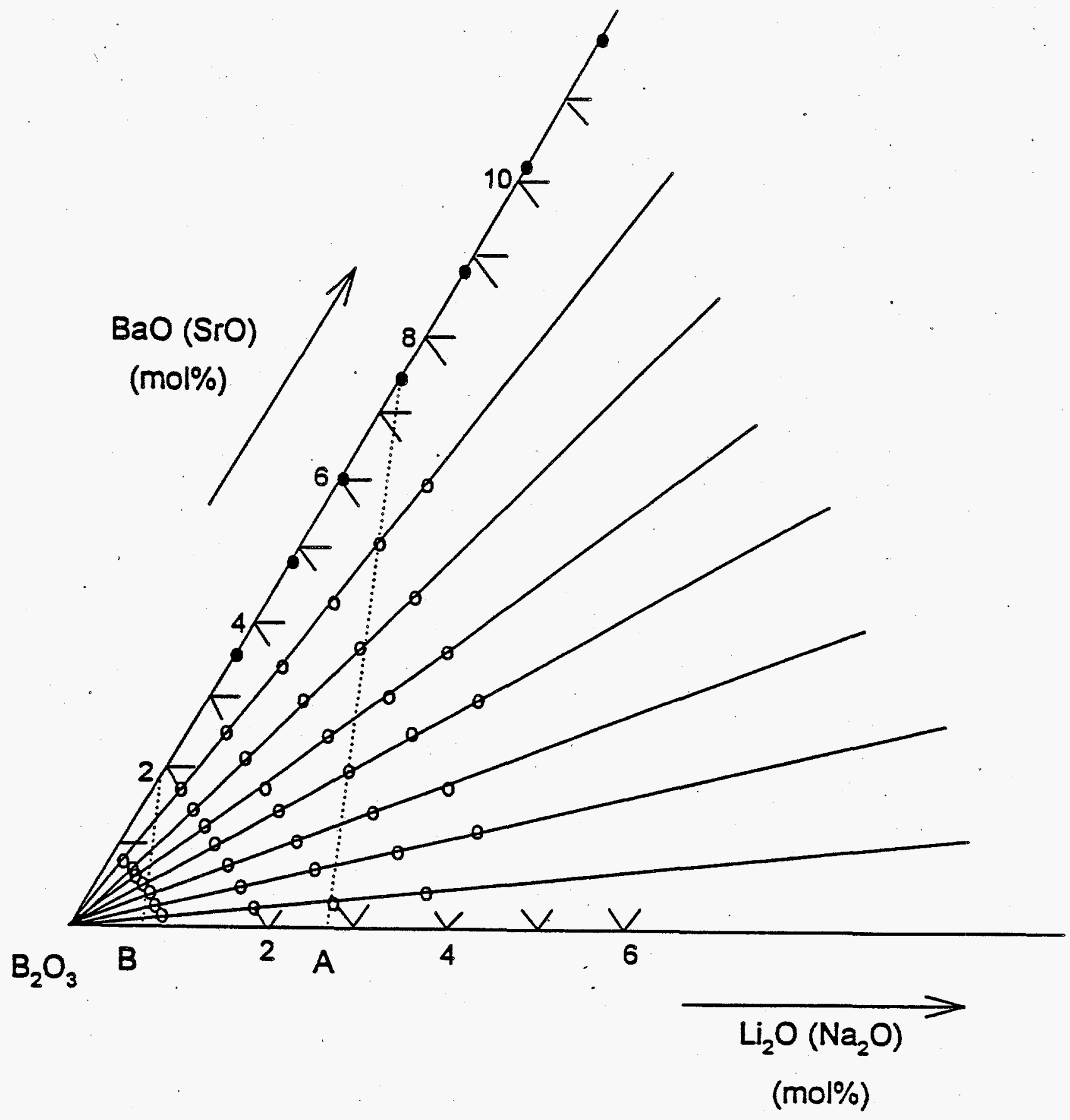

Fig. 2 . 


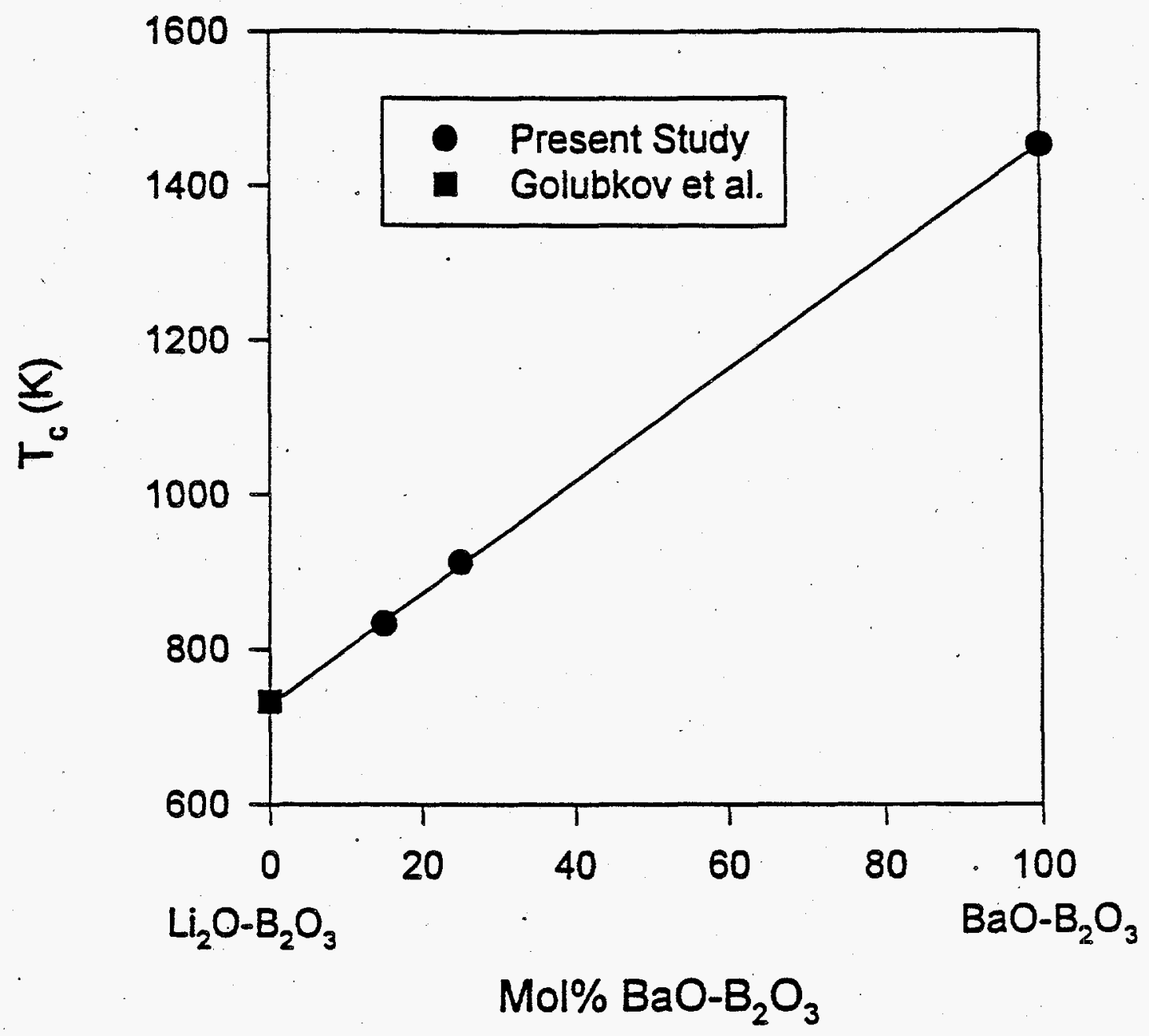

Fig. 3 


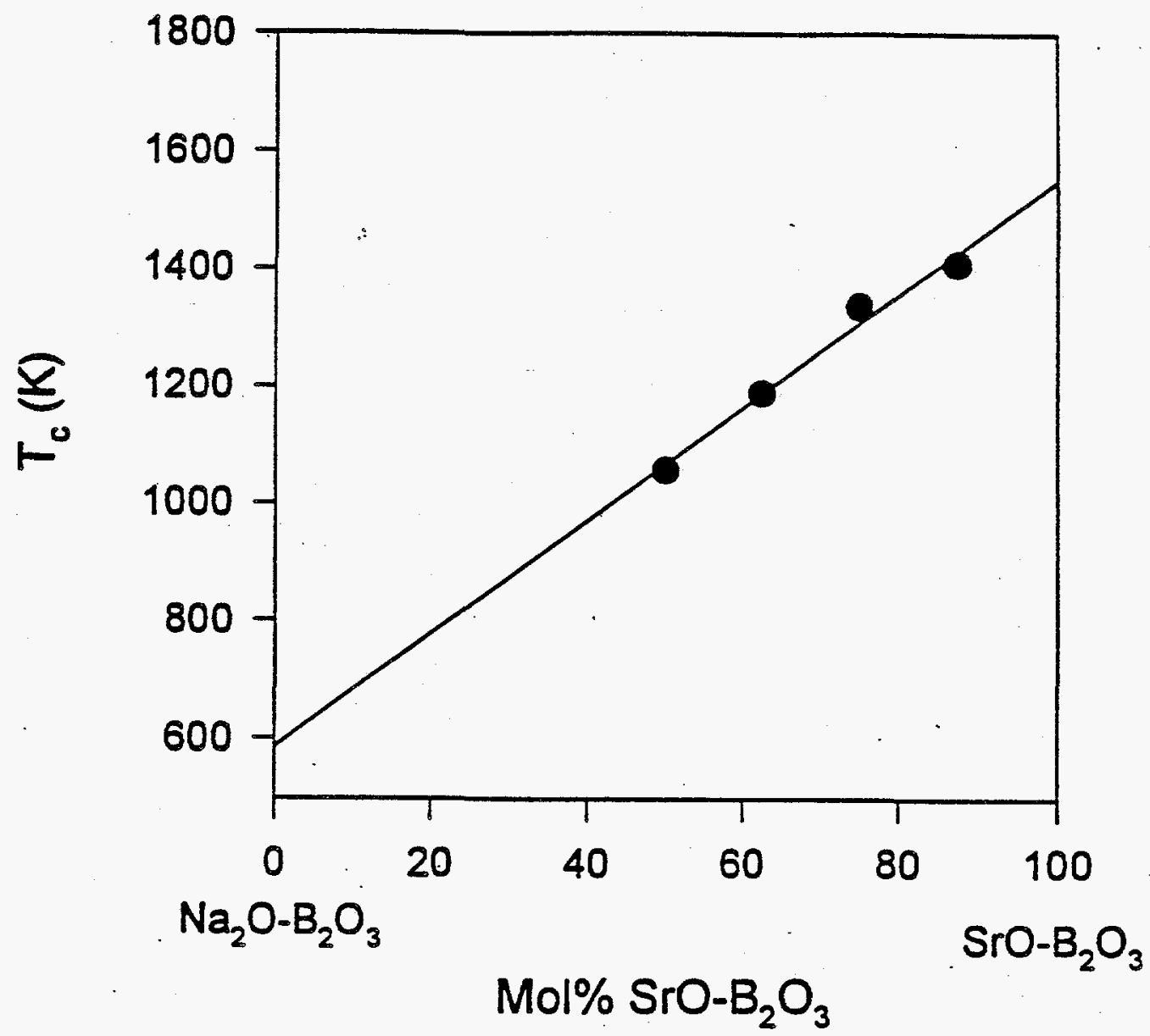

Fig. 4 


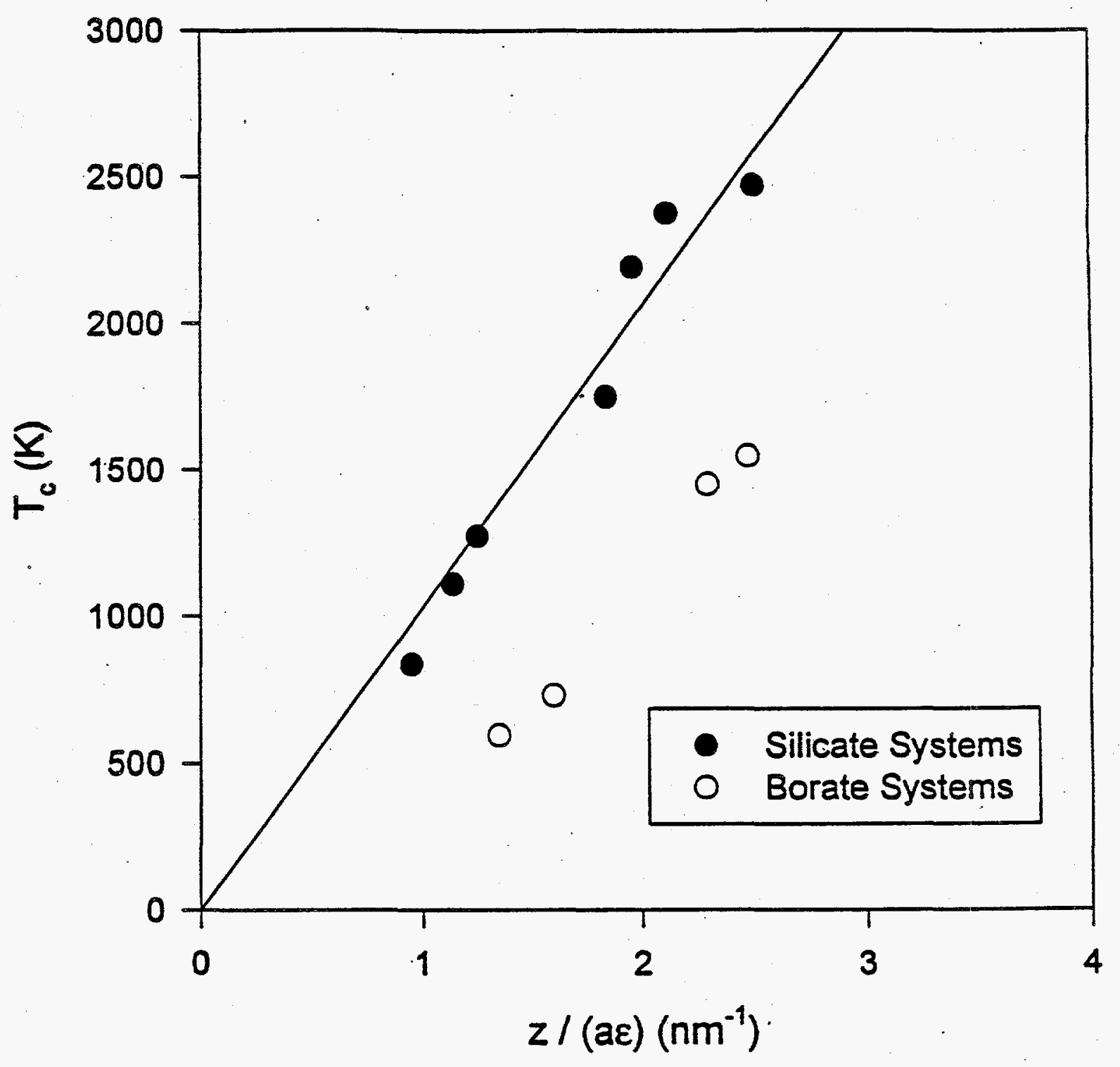

Fig. 5 


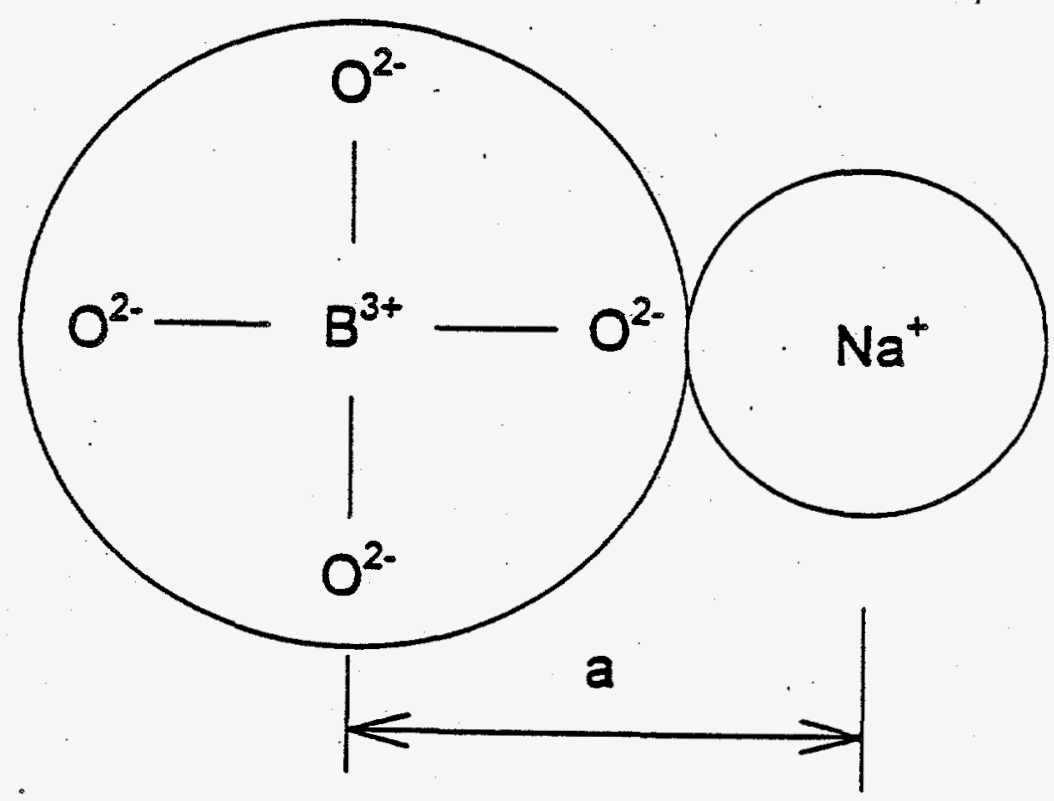

Fig. 6 


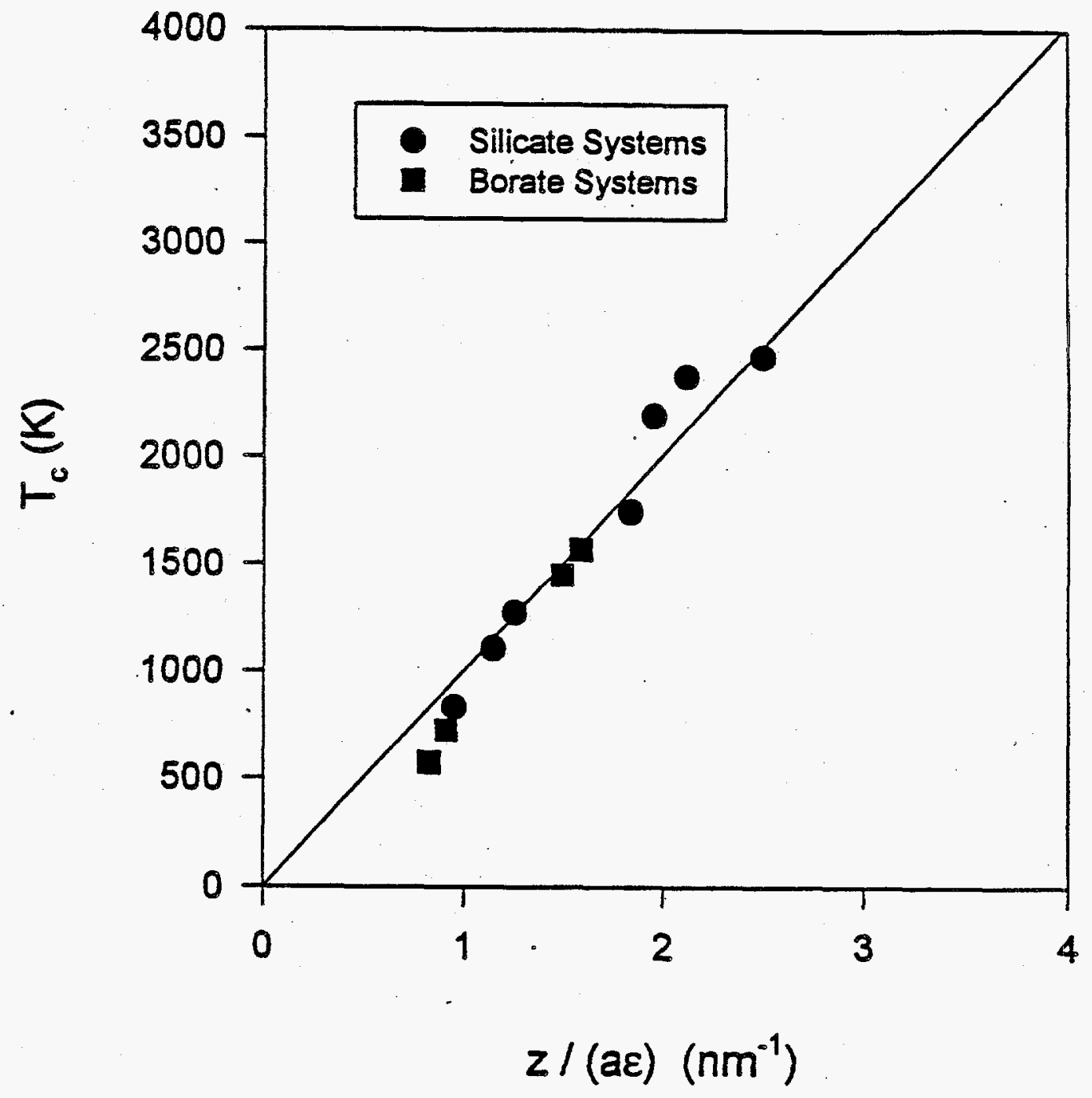

Fig. 7 


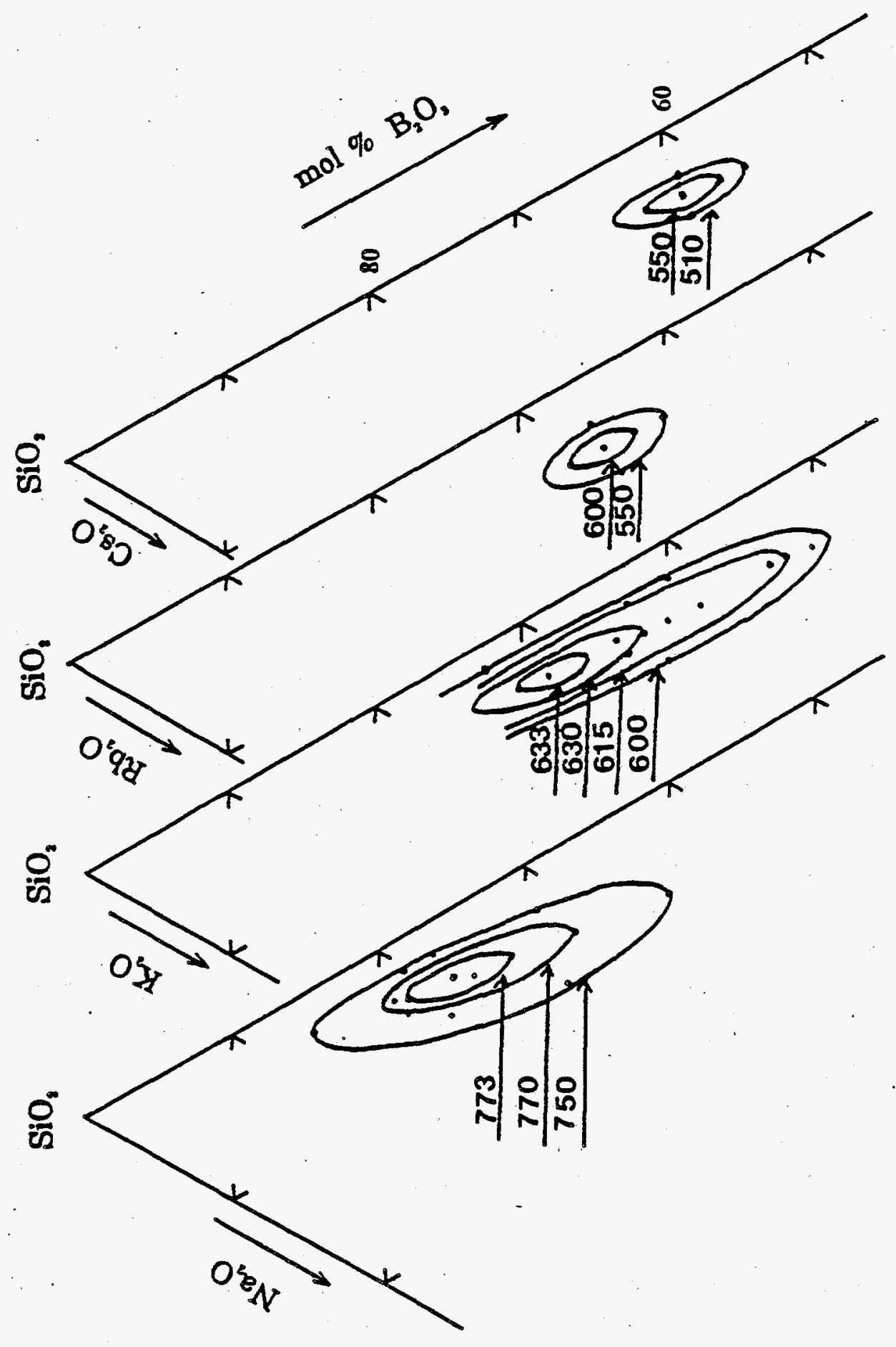

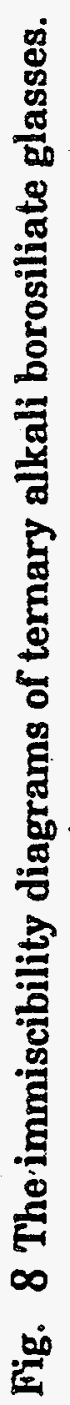

